
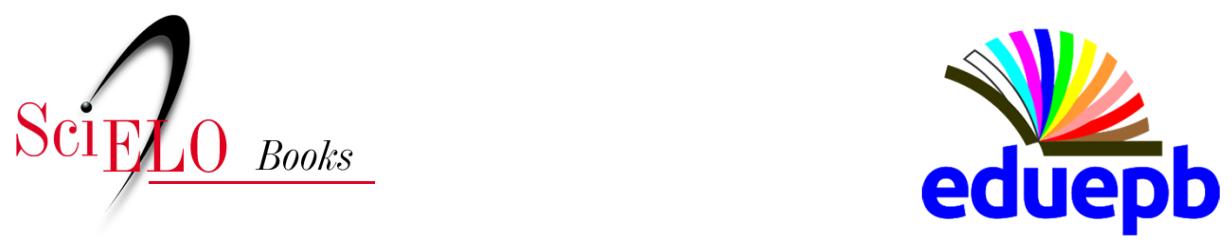

\title{
História e Natureza das Ciências \\ Elementos Implementados na Formação de Professores
}

\author{
Thaís Cyrino de Mello Forato
}

\section{SciELO Books / SciELO Livros / SciELO Libros}

FORATO, T. C. M. História e Natureza das Ciências: Elementos Implementados na Formação de Professores In: SILVA, A. P. B., and MOURA, B. A., eds. Objetivos humanísticos, conteúdos científicos: contribuições da história e da filosofia da Ciência para o ensino de Ciências [online]. Campina Grande: EDUEPB, 2019, pp. 227-263. ISBN: 978-85-78795-79-5. http://doi.org/10.7476/9786586221664.0008.

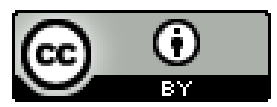

All the contents of this work, except where otherwise noted, is licensed under a Creative Commons Attribution 4.0 International license.

Todo o conteúdo deste trabalho, exceto quando houver ressalva, é publicado sob a licença Creative Commons Atribição 4.0.

Todo el contenido de esta obra, excepto donde se indique lo contrario, está bajo licencia de la licencia Creative Commons Reconocimento 4.0. 


\title{
HISTÓRIA E NATUREZA DAS CIÊNCIAS: ELEMENTOS IMPLEMENTADOS NA FORMAÇÃO DE PROFESSORES
}

\author{
Thaís Cyrino de Mello Forato \\ Universidade Federal de São Paulo - UNIFESP - Diadema \\ thaiscmf@gmail.com
}

\section{Introdução: pressupostos teóricos na construção de uma proposta formativa}

7 ducadores, filósofos e historiadores das ciências vêm se empenhando por empreender discussões sobre a historicidade das ciências no ensino de ciências, reconhecendo os inúmeros princípios formativos que tais debates promovem (MARTINS, R. 2006, PEDUZZI, 2001, MATTHEWS, 1992; PORTO, 2010; PUMFREY, 1991). Do mesmo modo, a literatura tem sido farta em identificar desafios, obstáculos e dificuldades dos mais variados escopos e em todos os níveis de formação, assim como em propor algumas sugestões para sua superação (ALLCHIN et al., 2014; BALDINATO, 2016; FORATO, 2009; MARTINS, A. 2007).

Entretanto, resultados dessa produção teórica ou de pesquisas empíricas conduzidas por especialistas permanecem muito distantes das salas de aula reais, tanto na Escola Básica, quanto na formação de professores. Algumas revisões bibliográficas atuais mostram que pouquíssima coisa mudou nos últimos anos (AZEVEDO; SCARPA, 2017; VITAL; GUERRA, 2017), a despeito de todo empenho que vários de nossos grupos de pesquisa 
vem empreendendo, no sentido de produzir material didático, implementá-lo, analisá-lo, ou mesmo em realizar propostas teóricas com recortes de episódios históricos, acompanhados por sugestões para utilizá-los em sequencias didáticas ${ }^{65}$.

Temas já bastante conhecidos no âmbito da literatura especializada, como a quase-história (WHITTAKER, 1979), a pseudo-história (ALLCHIN, 2004), prejuízos decorrentes das visões ingênuas sobre as ciências que predominam no ambiente escolar (BRUSH, 1974; GIL-PEREZ et al., 2001), continuam praticamente ausentes no ambiente de formação dos professores. Se para os especialistas tais temas já parecem um tanto obsoletos ou óbvios, é surpreendente constatar que ainda há propagação dos mitos do cientificismo e de versões historiográficas whigs na grande mídia, em boa parte dos materiais didáticos e no discurso de professores e de seus formadores (ACEVEDO-DIAS; GARCIACARNOMA, 2016; HOETECKE; SILVA, 2011; PAGLIARINI, 2007; ROSENTALSKY, 2018). Além disso, professores em formação e em serviço manifestam dificuldades em localizar materiais históricos adequados para a Escola Básica, ou ainda, para os casos em que encontram alguns textos históricos, sentem falta de orientações pedagógicas ou estratégias didáticas para seu uso (VITAL; GUERRA, 2016; OLIVEIRA; DRUMMOND, 2015; MOURA, B. 2012; SCHMIEDECKE, 2016).

Considerando as prerrogativas e recomendações oficiais para os usos da história das ciências (HC) no ensino (BRASIL, 1996; 2002a; 2002b; 2015), assim como vários desafios explicitados pela literatura em nosso contexto educacional, um projeto de pesquisa vem conduzindo a avaliação de diferentes propostas formativas,

65 Há uma vasta lista de artigos, capítulos de livros, dissertações, teses, trabalhos completos em atas de eventos e trabalhos de conclusão de curso com tais propostas, entretanto, há ainda uma dificuldade por parte de professores em localizar e utilizar tais materiais. Nesse sentido, uma pesquisa está sendo conduzida para organizar essas fontes, seguidas por orientações de como localizá-las (Santana e Forato, em andamento). 
implementadas na formação inicial de professores de ciências (física, química, biologia e matemática), na Universidade Federal de São Paulo, no campus Diadema. Tal projeto busca identificar elementos relevantes para preparar os professores para os usos da $\mathrm{HC}$ e da abordagem sobre a natureza das ciências (NDC) em sua futura prática profissional ${ }^{66}$.

Alguns pressupostos foram adotados para a construção da proposta, além dos inúmeros benefícios elencados pela literatura, mobilizados pelo uso da HC no ensino:

- Pesquisas já apontaram que uma única disciplina não é suficiente para preparar o professor para os usos didáticos da HC (MEDEIROS; BEZZERRA-FILHO, 2000; MARTINS, A. 2007);

- Ainda há mitos históricos clássicos, pseudo-história e visões ingênuas sobre a ciência em materiais didáticos, na mídia em geral, no senso comum, e no discurso de formadores, professores e estudantes (BALDINATO, 2016; GIL-PEREZ et al., 2001; MARTINS, R. 2006; PAGLIARINI, 2007);

- Há pouco material didático pautado em abordagens históricas e epistemológicas em perspectiva diacrônica e crítica, que sejam de fácil acesso aos professores, e mesmo quando são localizados, há uma dificuldade para sua implementação, carência de orientações ou adequação aos diversos contextos educacionais (BORGES, 2016; MARTORANO, 2012; VITAL; GUERRA, 2016);

- Alguns conflitos entre diferentes culturas predominam nos ambientes de formação de professores quanto às concepções sobre as ciências, sua história, sua didática específica e o ensino de seus aspectos epistêmicos e não

66 Projeto Universal CNPq - 454165/2014-5: "A história e a filosofia das ciências no ensino de ciências: implementando e avaliando propostas na formação inicial de professores". 
epistêmicos, ocasionando prejuízo aos processos formativos (FORATO et al., 2011; HOETTECKE; SILVA, 2011; HOLTON, 2003);

- As abordagens críticas da HC favorecem a compreensão dos produtos da ciência como constructos humanos, influenciados por questões políticas, econômicas e culturais de contextos específicos. Tal perspectiva apresenta uma ciência não neutra, dinâmica, produtora de certezas provisórias, passíveis de reformulações, de crítica, de contestação e de substituição de teorias por novos conhecimentos (ALLCHIN, 2011; BRUSH, 1974; HABERMAS, 2006; KUHN, 1961). Ao fomentar tal abordagem, pode-se promover a criticidade, a reflexividade emancipatória e contribuir para a promoção dos direitos humanos (ACEVEDO-DÍAS; GARCIACARMONA, 2016; D’AMBRÓSIO, 2007; FORATO et al., 2017; OLIVEIRA; QUEIROZ, 2015).

Considerando tais pressupostos e formulando algumas hipóteses, o projeto em pauta elencou alguns pilares como base, a partir dos quais as propostas didáticas foram se desdobrando:

1. Realizar uma inserção longitudinal da $\mathrm{HC}$ e da NDC, ao longo da formação dos professores, de modo que os licenciandos tenham contato com abordagens históricas, em diferentes disciplinas do curso. De acordo com as características de cada disciplina, a abordagem histórica atenderia a diferentes objetivos pedagógicos. Esse primeiro pilar é a principal hipótese da pesquisa, que o projeto Universal buscou avaliar;

2. Permitir que o professor vivencie o uso da $\mathrm{HC}$ para o ensino e aprendizado de conceitos científicos, teorias e modelos das ciências, ao mesmo tempo em que conhece diferentes episódios históricos, ampliando seu conhecimento da história de seu campo e de diferentes aspectos 
da NDC. A partir de exemplos históricos o futuro professor pode compreender a pluralidade metodológica e epistêmica das ciências (FORATO et al., 2017);

3. Preparar o professor para identificar e lidar com a pseudo-história e com as visões que reforçam os mitos do cientificismo no ambiente escolar e cultural (ALLCHIN, 2004; FORATO, 2013), evitando a perpetuação de uma educação de reprodução, que forma indivíduos subordinados, passivos e acríticos (D’AMBRÓSIO, 2007; MARTINS, R. 2006);

4. Promover atividades didáticas que permitam ao professor conhecer, avaliar e utilizar materiais historiográficos em perspectiva diacrônica e crítica, preferencialmente elaborado por especialistas, mas voltados ao ambiente educacional (FORATO et al., 2011), assim como vivenciar a prospecção de materiais e fontes históricas para construir planos de ensino, que podem ser adaptados e utilizados em sua futura prática profissional.

5. Promover a vivência da pluralidade de metodologias, de recursos didáticos e de abordagens educacionais, em ressonância com o uso da $\mathrm{HC}$, avaliando a consistência teórica entre elas e as visões de ciências que fomentam.

Desse modo, um projeto formativo foi idealizado visando inserir abordagens que perpassam objetivos pedagógicos voltados ao ensino e aprendizagem de conceitos científicos, ao debate de aspectos epistêmicos e não epistêmicos das ciências e à preparação de professores para usos didáticos da HC. Conforme explicita-se ao longo do texto, essas propostas favorecem, também, a perspectiva de que tal formação contribui para a promoção dos direitos humanos (FREIRE, 1996; FORATO; MOURA, 2017; OLIVEIRA; QUEIROZ, 2013; 2015; 2016). As propostas avaliadas buscaram responder às seguintes questões: 
- Como e quando poderíamos realizar a inserção da HC e da NDC?

- Que elementos poderiam orientar ações formativas?

- Em quais disciplinas? De que modo? Qual abordagem?

Desse modo, a descrição das propostas e as reflexões sobre elas, bem como pequenos extratos de resultados aqui apresentados, buscam exemplificar algumas das respostas propostas para essas questões.

\section{Metodologias: desenvolvendo, implementando e avaliando propostas}

Esta pesquisa ocorreu em um curso de formação inicial de professores, Graduação em Ciências - Licenciatura em Física, Química, Biologia ou Matemática, na Universidade Federal de São Paulo - campus Diadema. Os dois primeiros anos são comuns às quatro áreas e, nos dois últimos, os discentes optam pela especialidade, mas ainda compartilham algumas disciplinas. $\mathrm{O}$ projeto de pesquisa enfocou propostas implementadas no período entre 2015 a 2017, mas elas vêm sendo realizadas desde 2011.

O curso foi criado em 2010 e o aprimoramento do Projeto Político Pedagógico, bem como a revisão e construção de ementas curriculares, foi ocorrendo ao longo de seus primeiros anos, ao mesmo tempo em que a equipe docente estava sendo contratada. Isso permitiu a inserção de abordagens históricas e epistemológicas em distintos momentos (primeiro pilar da proposta), pois requereu que a proponente do projeto, autora deste trabalho, assumisse várias disciplinas ao longo do curso. Assim, foi possível implementar, observar e acompanhar algumas turmas ao longo de sua formação e avaliar propostas de HC e NDC, construídas a partir das hipóteses e dos pilares propostos. Os dados foram sendo avaliados ao longo dos anos, com diversas turmas e em diferentes disciplinas. 
A metodologia da pesquisa pauta-se na análise qualitativa, tendo a pesquisadora imersa no ambiente pesquisado (LUDKE; ANDRE, 1986; ERICSON, 1998). A vivência favoreceu a atuação reflexiva da professora-formadora-pesquisadora (PIMENTA; GHEDIN, 2012; DEMO, 2010), amparada pela observação participante (ANDRÉ, 2010) e sistematizada com apoio das narrativas autobiográficas (PASSEGGI et al., 2011). Desse modo, em algumas passagens deste texto, as ações descritas estarão na primeira pessoa do singular, quando se referirem à essas reflexões.

Diferentes instrumentos foram utilizados para a coleta de dados, permitindo a triangulação e a visão sistêmica parte-todo (ANDRÉ, 2010): caderno de notas, textos escritos pelos estudantes, trabalhos realizados em grupo, seminários apresentados, manifestações espontâneas de estudantes ao longo das aulas e uma entrevista semiestruturada, realizada com os alunos de uma turma de Práticas Pedagógicas de Física II, em 2015. Para analisar o conteúdo das entrevistas foi utilizada a análise de conteúdo de Bardin (2000). Tal entrevista foi realizada reservadamente, por uma pesquisadora mestranda da Universidade Federal do ABC e os estudantes tiveram suas identidades preservadas ${ }^{67}$.

A narrativa autobiográfica fundamenta o relato da implementação das propostas formativas, já manifestando reflexões, conjecturas e alguns resultados ao longo do texto.

O quadro 1 traz a síntese das disciplinas em que as propostas foram apresentadas, destacando a carga horária total da disciplina e as horas dedicadas explicitamente a temas e abordagens de história e natureza das ciências.

67 A transcrição da entrevista foi custeada pelo Projeto Universal do CNPq e foi objeto desta análise que realizei para este trabalho. Os aspectos éticos envolvendo os sujeitos de pesquisa, bem como o termo de livre e esclarecido previsto no Projeto, foram aprovados pelo Comitê de Ética em Pesquisa da Unifesp, para a coleta de dados apenas na Unifesp - Diadema. A mestranda que coletou os dados realizou outras análises em sua dissertação (BORGES, 2016). 
Quadro 1 - História das Ciências na Formação de Professores.

\begin{tabular}{|c|l|c|c|c|c|c|}
\hline Semestre & Disciplinas & $\begin{array}{c}\text { Áreas do } \\
\text { curso }\end{array}$ & $\begin{array}{c}\text { Carga } \\
\text { Horária } \\
\text { (Horas) }\end{array}$ & $\begin{array}{c}\text { Horas para } \\
\text { HC e NDC } \\
\text { implícita e } \\
\text { explicitamente }\end{array}$ & $\begin{array}{c}\text { Anos de imple- } \\
\text { mentação dessa } \\
\text { proposta }\end{array}$ & Pilares \\
\hline $3^{\circ}$. & Física III & 4 áreas & 72 & 52 & 2011 e 2012 & 1,2 \\
\hline $3^{\circ}$. & $\begin{array}{l}\text { Integração das } \\
\text { Ciências III }\end{array}$ & 4 áreas & 16 & 8 & 2012 & 1,2 \\
\hline $4^{\circ}$. & Física IV & 4 áreas & 72 & 46 & 2011 e 2017 & 1,2 \\
\hline $5^{\circ}$. & $\begin{array}{l}\text { Práticas Pedagógi- } \\
\text { cas de Ciências }\end{array}$ & 4 áreas & 36 & 8 & $\begin{array}{c}2012,2013, \\
2014\end{array}$ & $1,3,4$ \\
\hline $6^{\circ}$. & $\begin{array}{l}\text { Práticas Pedagógi- } \\
\text { cas de Física I }\end{array}$ & Física & 72 & 20 & 2012 até 2018 & $\begin{array}{c}1,2, \\
4,5\end{array}$ \\
\hline $7^{\circ}$. & $\begin{array}{l}\text { Práticas Pedagógi- } \\
\text { cas de Física II }\end{array}$ & Física & 72 & 30 & 2013 até 2018 & $\begin{array}{c}1,2,3 \\
4,5\end{array}$ \\
\hline $8^{\circ}$. & $\begin{array}{l}\text { Práticas Pedagógi- } \\
\text { cas de Ciências à } \\
\text { Distância }\end{array}$ & 4 áreas & 72 & 24 & 2013 & $1,3,5$ \\
\hline
\end{tabular}

Fonte: Autora, pesquisadora proponente do projeto e professora das disciplinas

Como se pode observar no quadro acima, foram realizadas inserções longitudinais da $\mathrm{HC}$ e da NDC ao longo da formação dos professores, conforme previa o primeiro pilar da proposta. Por ter participado da construção do curso, pude elaborar e implementar propostas, bem como acompanhar vários grupos de estudantes, observando até que ponto os objetivos formativos trabalhados em uma disciplina manifestavam-se posteriormente em outras aulas, em outros momentos de sua formação. Como previa a proposta, a inserção da $\mathrm{HC}$ e NDC em cada disciplina atendeu a diferentes propósitos formativos ${ }^{68}$.

68 Na grade curricular do curso havia a disciplina de História da Ciência até 2018, que foi ministrada por outros docentes, com formação em Filosofia. Alguns professores de disciplinas como Mecânica Quântica ou Eletromagnetismo ou Estrutura da Matéria, dos semestres finais do curso, chegaram a utilizar artigos de história das ciências em suas aulas, mas ainda não realizamos nenhuma pesquisa para avaliar como tais abordagens dialogam com este projeto. É um plano que está em pauta em 2019, para projetos futuros. 
A seguir, uma descrição sucinta das propostas implementadas por mim, assim como algumas reflexões sobre resultados, buscando também oferecer subsídios para quem tiver interesse em utilizá-las.

\section{Vivenciando 0 aprendizado de ciências com a história das ciências}

Nas propostas iniciais para Física III e IV, os textos com episódios de HC, escritos por historiadores das ciências, majoritariamente para o ambiente educacional, foram utilizados para ensinar conceitos de física, química, biologia e proporcionavam, também, reflexões explícitas sobre a ciência. Nesse momento, além de buscar favorecer a aprendizagem do conteúdo científico e epistemológico, os estudantes vivenciavam exemplos de como a HC pode ser usada para ensinar ciências. Portanto, a proposta enfatiza o terceiro pilar da proposta, mas perpassa os demais.

Essas duas disciplinas possuem carga horária de 72 horas, sendo 4 horas semanais, em um único dia. Há 16 horas de aulas de práticas experimentais que ocorreram no laboratório, e 4 horas em um outro dia foi reservado para trabalho de campo em um museu de ciências. Nas 52 horas restantes de aulas teóricas, nas turmas de 2011 e 2012 de Física III, por exemplo, havia alguns momentos reservados para seminários dos alunos sobre história da termodinâmica ou atividades envolvendo história da óptica. Os textos históricos estavam relacionados aos conceitos físicos que estavam sendo trabalhados e a $\mathrm{HC}$ surgia para contextualizá-los. Essas abordagens permitiam, também, discutir aspectos epistemológicos de sua elaboração e aspectos não epistêmicos do contexto histórico que influenciavam a ciência e eram influenciados por ela. Além dessas abordagens, havia aulas expositivas teóricas; resolução de exercícios; análise de limitações conceituais ou epistêmicas em conteúdos de vídeos do Youtube; de episódios 
de Beakman ${ }^{69}$; discussão sobre visão de ciências na modelização de fenômenos a partir do uso do simulador $\mathrm{PHET}^{70}$; vivência de um minicurso sobre história da luz implementado na escola básica, com atividades envolvendo debates, teatro, demonstrações de fenômenos e leituras de textos. Diferentes recursos e abordagem buscavam o enfoque contextualizado dos conteúdos conceituais de física. O conteúdo histórico e epistemológico era explícita e implicitamente trabalhado e constou nas avaliações e no exame final.

Acompanhei os estudantes dessas duas primeiras turmas do curso em outras 4 disciplinas, que também foram ministradas por mim (veja quadro 1). Alguns traziam reflexões sobre a NDC espontaneamente, em diferentes situações, e a maioria dos demais apresentavam visões coerentes sobre a NDC, quando perguntados. Como professora pesquisadora, que reflete sobre a própria prática, pude observar a transferência de conteúdos para novos conteúdos, situações e contextos, o que traz a satisfação de reconhecer um aprendizado significativo acerca de uma visão reflexiva e crítica sobre as ciências (MOREIRA, 2013).

Nas disciplinas de Física IV, em 2011 e 2017, inseri abordagens metodológicas similares às das edições de 2011 e 2012 de Física III. Observei resultados que também mostravam benefícios propiciados pela abordagem da $\mathrm{HC}$.

Entretanto, um resultado relevante dessas vivências foi observar uma divisão nas turmas. Boa parte dos alunos manifestou boa aceitação da diversidade metodológica nessas disciplinas

69 Vídeos de divulgação das ciências para pré-adolescentes, transmitidos pela TV cultura, que encantou vários dos alunos que foram cursar Ciências, segundo eles próprios.

70 Simulações interativas em Ciências e Matemática, desenvolvidas pela Universidade do Colorado, nos Estados Unidos: < http://phet.colorado.edu/ pt_BR/>, acesso em 3/3/2011. 
e se engajou com entusiasmo nas abordagens históricas, relatando a superação de dificuldades com conteúdos de física e matemática. Porém, havia um grupo ${ }^{71}$ que não se interessava e dizia preferir as aulas teóricas mais próximas às tradicionais, os experimentos no laboratório e a resolução de exercícios. Isso corrobora pesquisas sobre a diversidade de perfis dos estudantes e a necessidade de mobilizarmos um pluralismo metodológico no ensino de ciências, buscando contemplar o espectro de questões com as quais lidamos em nossa prática profissional (LABURÚ; ARRUDA; NARDI, 2003).

\section{Identificar e lidar com a pseudo-história}

A proposta para a disciplina de Práticas Pedagógicas de Ciências enfatiza o terceiro pilar da proposta, além de ser fundamental para a totalidade do projeto formativo, contribuindo para os demais 4 pilares. Nos anos de 2012, 2013 e 2014, quando coordenei a disciplina e ministrei o tema da pseudo-história, 4 aulas de 2 horas foram utilizadas, do total de 36 horas do curso. Os resultados da proposta com a primeira turma foram publicados em Forato (2013).

A concepção inicial partia de uma leitura prévia Gil-Perez et al., (2001), que fundamentava a discussão do primeiro encontro, sobre as concepções sobre ciências, educação, aprendizagem, metodologias, recursos didáticos e avaliação. Como leitura extra sala para a próxima aula, o segundo encontro, os estudantes que optaram por biologia liam Martins, L. (1998); os de física Martins, R. (2000); e o artigo de Vidal e Porto (2007) era o indicado para os discentes de química. $\mathrm{Na}$ aula a seguir, eram discutidos os mitos históricos propagados em materiais didáticos e na grande mídia,

71 Alguns alunos desse grupo estavam interessados em prestar vestibular para medicina ou para o ITA, o que também influenciava em suas preferências. 
e as visões ingênuas e estereotipadas que eles fomentavam. Para o terceiro encontro, a leitura de trechos de Allchin (2004) ou de Forato et al. (2011), buscavam alicerçar os debates sobre a pseudo-história e, juntamente com Gil-Perez et al. (2001), permitiam que construíssemos categorias de análise para avaliar materiais didáticos. A partir daí os estudantes preparavam uma análise da abordagem da $\mathrm{HC}$ em livros didáticos do fundamental II, apresentada na aula seguinte.

Os conteúdos desse processo vivido nessa disciplina surgiam em outras aulas e em diferentes oportunidades. Alguns estudantes que já atuavam como professores, ou alguns que vieram a assumir aulas, solicitavam-me material "confiável" para usarem, explicitando sua preocupação em evitar a pseudo-história. Alguns alunos foram convidados por outro docente do curso a avaliarem o conteúdo histórico em materiais de divulgação científica. Segundo o colega, as análises apresentavam fundamentação adequada para as críticas elaboradas.

\section{Práticas Pedagógicas de Física: refletir, debater, construir e praticar}

A disciplina de Práticas Pedagógicas de Física I é voltada prioritariamente para os Licenciandos em Física, e ocorrem em 4 horas aula/semana, integrando 72 horas semestrais. Essa disciplina acentua os pilares 4 e 5 , e retoma os objetivos dos demais. Uma das semanas discute a NDC explicitamente, a partir das concepções sobre ciências, nos graus de liberdade dos estudantes nas práticas experimentais (CARVALHO, 2010). Outro tema em que a $\mathrm{HC}$ e a NDC são explicitamente trabalhadas é o da Física como cultura, a partir da interface entre Física e Arte. Debatemos os textos de Zanetic (2006) e Reis et al. (2006) a partir de seminários dos alunos e na próxima aula os estudantes ministram seminários com outros textos prospectados por eles. No terceiro encontro, os alunos apresentam planos de ensino para a escola 
básica, a partir da interface entre conceitos de física e a arte. Nas aulas, são retomadas as visões de ciências e de sua construção sociohistórica, trabalhadas em outras disciplinas, avançando na complexificação desses temas. Há inclusive, um esforço por mobilizar enfoques estudados nas disciplinas de História da Ciência e Teoria do Conhecimento que ficam sobre a responsabilidade de outros docentes. Conseguimos estabelecer pontes interessantes, a partir de comentários trazidos pelos discentes, como entre a concepção crítica sobre a história da ciência de Habermas (2006) com as perspectivas historiográficas que trabalhamos.

Essa disciplina de Práticas Pedagógicas de Física I tem produzido trabalhos muito interessantes, sendo que alguns motivaram pesquisas que se tornaram Trabalhos de Conclusão de Curso em História da Ciência e outros foram apresentados em eventos científicos ou foram publicados como artigos (p.e. CARDOSO, 2014; PEREIRA; FORATO, 2014; CARDEIRA, 2015; GUILGER; FORATO, 2015; NEVES et al., 2016; FERNANDES et al., 2017).

Como em outros momentos do projeto formativo, o enfoque histórico não é unanimidade, alguns estudantes não demonstram interesse pelo tema, tampouco acreditam que o utilizarão em sua prática, mas reconhecem que desenvolveram uma visão mais crítica e reflexiva, e que é relevante saber reconhecer a pseudo -história. Apesar das críticas, os dados de 2015, apresentados na próxima seção, mostram visões bem informadas sobre os usos da $\mathrm{HC}$ no ensino.

As aulas de Práticas Pedagógicas de Física II, outra disciplina com 72 horas no semestre, partilham alguns temas com as aulas das Práticas Pedagógicas de Química II, quando ambas as docentes compartilham a sala de aula. Os temas comuns perpassam a NDC, contextualização, interdisciplinaridade, Ciência-Tecnologia-Sociedade e HC no ensino. Para pensar 
o enfoque da $\mathrm{HC}$ no ensino, especificamente, consideramos os seguintes pressupostos:

- Os estudantes vivenciam a HC para ensino de conceitos científicos nas disciplinas básicas, a identificação da pseudo-história, bem como estratégias para lidar com ela nas Práticas Pedagógicas de Ciências, e, reforçam a ideia da ciência como integrante da cultura nas Práticas Pedagógicas de Física I;

- Para contemplar os pilares 4 e 5, o projeto propõe que é necessário trabalhar a prospecção de material histórico diacrônico e crítico (MARTINS, R. 2001; 2004; 2006) acerca de episódios históricos e a construção de uma proposta para abordá-lo no Ensino Médio.

As propostas para essa disciplina de Práticas Pedagógicas de Física II têm variado um pouco ao longo dos anos, mas basicamente contemplam esses pressupostos. Em 2015, iniciamos com debates sobre dois textos com enfoques historiográficos bem distintos, o que permitiu retomar a consistência entre visões sobre NDC na educação científica; dificuldades da $\mathrm{HC}$ como recurso didático; desafios para a seleção de material. A seguir, apresentamos cinco artigos para os estudantes conhecerem exemplos de atividades didáticas utilizando a $\mathrm{HC}$, recomendando que a leitura fosse direcionada para as atividades. Em uma próxima etapa, os estudantes utilizavam o texto sobre Benjamin Franklin (SILVA; PIMENTEL, 2008) para a construção de uma proposta didática para a escola básica.

Alguns dos dados obtidos com essa turma, por meio de uma entrevista, serão apresentados na próxima seção, e destacam dificuldades e obstáculos enfrentados na formação de professores, e, por outro lado, a consistência dos argumentos que os estudantes usam, mesmo quando fazem críticas ao uso da $\mathrm{HC}$ na escola básica. 


\section{Práticas Pedagógicas de Ciências à Distância: onde chegamos?}

A minha participação na disciplina de Práticas Pedagógicas de Ciências a Distância ocorreu apenas em sua primeira edição, em 2013. Ela ocorre ao final da graduação e foi onde pude observar a manifestação de discentes que haviam, ou não, cursado as Práticas Pedagógicas anteriores.

A maior parte da carga horária ocorria virtualmente, com a participação de docentes e estudantes. As orientações, indicação de materiais e atividades eram realizadas no Moodle, quando os discentes vivenciavam o ambiente virtual de aprendizagem (AVA), no qual poderiam vir a trabalhar. Fiquei responsável pelo módulo 1 da disciplina, que tinha como objetivo central promover a reflexão sobre as concepções de ciências e de matemática, as visões sobre a construção desses saberes e de seu ensino/aprendizagem. Debatemos justificativas para os enfoques sociohistóricos das ciências, bem como a sua relação com inúmeros aspectos da cultura atual. Ou seja, o módulo sob minha responsabilidade permitiu que eu fizesse uma avaliação e um fechamento para todo meu projeto de formação, por meio do qual pude observar os argumentos dos estudantes que já haviam cursado as propostas anteriores, tendo contato com os pilares propostos no projeto, aplicando-os na reflexão e na análise crítica de alguns recursos didáticos midiáticos. Isso trouxe um contraste com aqueles que anteciparam essa disciplina.

No módulo 1, iniciamos com a leitura de alguns textos sobre ensino de ciências à distância, orientada por questões norteadoras, direcionando também para a NDC. A seguir, debatemos sobre o processo de construção do conhecimento em um fórum, de modo a promovermos uma interação dialógica, mediante uma perspectiva socio-histórica-cultural. Em uma perspectiva freiriana, o diálogo foi o elemento propulsor da colaboração, em um espaço privilegiado para a construção compartilhada do conhecimento. 
Uma análise de vídeos foi apoiada por questões que favorecem a reflexão sobre esse recurso midiático, bastante pertinente ao EAD.

Como nesse curso de Graduação em Ciências da Unifesp, não há pré-requisitos para as disciplinas, os debates nesse fórum constituíram-se um resultado muito relevante para o projeto. Mais do que nas outras atividades dessa disciplina, o fórum explicitou as diferenças nos argumentos entre os estudantes que haviam cursado as propostas anteriores do projeto, daqueles que não haviam tido contato com uma ou outra proposta. Alguns discentes estavam cursando a segunda graduação, haviam dispensado parte das disciplinas básicas, por exemplo, e não tinham cursado as outras práticas pedagógicas. Suas visões sobre as ciências e matemáticas eram majoritariamente ressonantes com as perspectivas criticadas por Gil-Perez et al. (2001), sobre as visões deformadas das ciências.

Ainda que se possa considerar que era esperado isso ocorrer com os alunos "novos", e que os licenciandos que vivenciaram as propostas anteriores reproduziriam o que a professora esperava obter, essa análise parece-me muito superficial. Muitos estudantes passam por temas, abordagens, conceitos e sequer conseguem manifestá-los em outros contextos, mesmo quando perguntados. Nessa disciplina, a maioria dos licenciandos, que já haviam cursado disciplinas com as propostas formativas do projeto com $\mathrm{HC}$, apresentou argumentos bem fundamentados, incorporando e transferindo conceitos historiográficos e epistemológicos que haviam sido estudados em outras roupagens. Inclusive, licenciandos da biologia, que não cursaram as Práticas Pedagógicas de Física I e II, mas apenas as Físicas III e IV e as Práticas Pedagógicas de Ciências, debateram ativamente no fórum, manifestando visões epistêmicas bem fundamentadas. Não raro, conteúdos das propostas anteriores eram mobilizados. Claro que isso não ocorreu com 100\% dos estudantes, mas não é exagero dizer que, naquele momento, o fórum foi um dos instrumentos mais relevantes para avaliar o projeto, revelando resultados consistentes com os pressupostos e pilares formativos do projeto. 


\section{Resultados de um recorte: com a palavra, os estudantes}

A entrevista semiestruturada, gravada em vídeo, foi realizada por uma mestranda da Universidade Federal do ABC, minha orientanda à época, com 16 licenciandos de física, sendo 4 do período vespertino e 12 do período noturno, que cursaram a Prática Pedagógica de Física II, em 2015. A Análise de Conteúdo (BARDIN, 2000) foi utilizada para analisar as mensagens comunicadas nas respostas, a partir da transcrição da gravação dos vídeos.

$\mathrm{Na}$ análise dos dados busquei identificar elementos a priori e a posteriori que possam ter sido formativos. Ao percorrer as manifestações dos estudantes, considerei como elementos a priori aqueles que expressavam os objetivos e hipóteses do projeto. Por exemplo, manifestações sobre identificar a pseudo-história, saber lidar com ela, reconhecer contribuições da $\mathrm{HC}$ para aprender física/ciências e sobre a NDC, saber localizar material e ter ideia de como utilizá-lo. Há também elementos já bem referenciados pela literatura sobre dificuldades esperadas, como pouco tempo para aulas de física, dificuldade para localizar material, dificuldade para desenvolver propostas, receio de preconceito dos alunos, diretor, coordenador e dos pais.

De fato, tais elementos a priori surgiram nas mensagens comunicadas pelos discentes, assim como identifiquei outros elementos a posteriori ampliando os resultados esperados.

A partir da leitura flutuante na transcrição da entrevista foi possível sintetizar nove categorias. Num segundo momento, a exploração mais detalhada do material, buscando destacar unidades de registro e unidades de conteúdo, agrupei as mensagens em cinco categorias, de modo a atender às questões de pesquisa do projeto, inclusive apontando aspectos que precisam ser aprimorados:

1. Pseudo-história, mitos, historiografia: Saber identificar, problematizar, vantagens e desvantagens. 
2. Contribuições da HC para a formação de estudantes e para o ensino de ciências.

3. Dificuldades na construção e/ou implementação de propostas.

4. Sugestões de estratégias didáticas.

5. Lacunas: aspectos trabalhados que não ficaram claros.

Para este trabalho, selecionei alguns exemplos de falas dos estudantes, para ilustrar algumas dessas categorias.

$\mathrm{Na}$ categoria 1, envolvendo o aprendizado sobre a pseudo -história, propositadamente, escolhi trechos daqueles estudantes que disseram sentir dificuldades em identificar material, em realizar propostas didáticas para a escola básica. Alguns chegam a mencionar que não se sentem preparados e que não utilizarão a $\mathrm{HC}$ em sua prática profissional. Entretanto, é possível observar que as críticas que fazem são bem fundamentadas e que eles próprios apresentam sugestões e capacidade de análise:

E1: [...] pra gente não correr risco de transmitir a pseudo-história, né? A pseudo-ciência, [...] Todo lugar que você vai e tem a historinha do Arquimedes, e a gente sabe que aquilo ali é pseudo-história.

E3: [...] a pseudo-história também tem uma motivação, ela vai servir pelo menos pra gente mostrar que não é certo, a forma errada de se fazer a história. E muitas vezes os livros didáticos trazem essa pseudo-história, então a gente tem também que saber aproveitar, já que ela está ali no livro.

E5: Muita gente tenta passar a vida do cientista perfeito [...] O cara tirou aquilo de uma visão rápida ...

E8: [...] fala sobre a dispersão que o raio provoca, mostra bem que eles atiram arpões com 
fio no meio da nuvem pra estudar a descarga elétrica, a imagem é forte, mas você confronta isso com a imagem do raio... imagem do Franklin lá nos desenhos ... aí você fala pra criança "Você acha que realmente $[. .$.$] acon-$ teceu isso, ele empinou pipa no meio de uma tempestade?". [trecho em que o aluno critica a narrativa em livros didáticos, sobre o experimento de Franklin com raios].

E 4: O pai da descoberta [...] sempre fez isso sozinho. Foi por acaso [...] o ponto de vista ingênuo dos textos é demais [...].

Os outros estudantes manifestam mais confiança em saber identificar e problematizar a pseudo-história, chegando a sugerir que o trabalho crítico com os mitos históricos pode ser uma estratégia didática importante, para fomentar a criticidade do aluno.

$\mathrm{Na}$ categoria 2, os estudantes destacam várias contribuições da HC. Novamente, selecionei alguns exemplos dos estudantes mais críticos com relação às abordagens da $\mathrm{HC}$ na escola básica, pois observei que mesmo eles, reconhecem alguns dos benefícios:

E3: Ele [ o professor] até sabe que é interessante, ele faz um curso, por exemplo, de história da ciência, ele vai ver que é interessante, que a história da ciência tem as características, além disso tudo que a gente falou, ela vai ajudar a reforçar um conceito, ela pode ajudar o aluno entender que a ciência ela é [..] ela pode ser feita por qualquer um, as pessoas que fizeram ciência eram pessoas comuns como nós. Então, tudo isso ele vai aprender, o professor aprende. Ele vê que é legal, ele vê que isso vai fazer uma referência para o aluno.

E6: [...] muita coisa que precisava realmente ser mostrada pras pessoas, a questão mais humana do cientista, como ele realmente 
trabalha pra poder chegar aos resultados, como eles trabalham em grupo, as críticas que eles recebem, os erros que eles cometeram [...].

E7: Aí nessa aula saiu o seguinte, que a gente tem que realmente ser bem crítico em tudo que a gente lê, né? $\mathrm{E}$ pra você aplicar uma aula de História das Ciências, você não pode ser [...] não pode tomar o partido, como eu tomava quando eu dava aula e não tinha tido essa Licenciatura aqui né, eu venho do bacharelado [...], que é o que eu sempre acreditei, assim,: você olhava pra uma coisa da USP, da Unicamp ou de algum 'bambambã', beleza, vou acreditar né?

As dificuldades que compõem a categoria 3 são, majoritariamente, aquelas já apontadas pela literatura, pouco tempo didático, dificuldade para localizar material, para desenvolver proposta, e alguns alunos enfatizam que as propostas teóricas não são adequadas ao mundo real:

E3: só que as propostas que a gente vê nos artigos elas são muito irreais, pra sala de aula de Ensino Médio do Ensino Público, pelo menos na escola em que eu fui fazer estágio, os colegas que já estão dando aula têm também [essa opinião].

Os discentes elaboram muitas sugestões sobre como utilizar a HC no ensino médio, compondo a categoria 4. Apresento apenas um breve exemplo, de um dos alunos mais críticos à abordagem histórica no ensino médio:

E8: Eu acho que uma alternativa é você tentar desconstruir o mito através de um experimento. Tem a história de mergulhar a coroa na água $[. .$.$] tenta replicar isso com os alunos$ 
com um balde, [...] A diferença ia ser muito grande. Você tenta desconstruir o mito, né. $\mathrm{Na}$ hora assim. [...] Mas o que for possível e se você fizer [...] talvez o do Franklin (risos de todos) você traga alguma forma de você medir a carga. Aí você fala "Oh, esse choquinho que você tomou aqui foi meio forte, num foi? 12 volts, o raio é mais de um milhão, assim, vai ser bem mais forte. Se o Franklin tivesse tomado um desses, ele teria história pra contar? Não. Tenta desconstruir, dessa forma que eu tentaria, desconstruir o mito, quebrar o mito na sua raiz. $\mathrm{O}$ que faz ele interessante, mas não é verdade.

$\mathrm{Na}$ categoria 5, as lacunas identificadas na formação dos estudantes, foi possível perceber aspectos que precisam ser melhor trabalhados. Um dos discentes expressa a dificuldade que percebi em outros alunos, a partir de perguntas e críticas que faziam durante a aula, sobre como implementar a HC na escola básica.

Essa turma não teve oportunidade de vivenciar o curso sobre história da luz que foi aplicado no ensino médio, por exemplo, como as turmas que cursaram física III em 2011 e 2012. Nesse sentido, a análise da proposta de inserção longitudinal da HC, em que acompanhei turmas que fizeram diferentes percursos, tendo contato ou não com propostas formativas do projeto, permitiu observar esses resultados diferentes. Os alunos das 2 turmas que tiveram oportunidade de vivenciar o pilar 2, o uso da $\mathrm{HC}$ para o ensino e aprendizado de conceitos científicos, teorias e modelos das ciências na Física III, exatamente a partir de uma proposta aplicada na escola básica, tiveram uma percepção diferente, e chegavam a utilizar estratégias daquele curso, em seus planos de ensino. Nessa turma de 2015, que não vivenciou o curso, alguns alunos tinham críticas e certa incredulidade de que isso pudesse ser feito: 
E3: A grande dificuldade, não é fazer a proposta, é imaginar como vai aplicar essa proposta nos prazos que você tem na escola. Então, essa que é a grande dificuldade, você percebe todos [...] as estratégias diferenciadas, sempre coloco lá nas minhas apresentações, todas essas estratégias diferenciadas você tem que pensar isso, quando que eu vou falar isso, quando eu vou ter um tempo pra falar isso? Eu acho que esse é o grande desafio, é a grande dificuldade. $\mathrm{Na}$ nossa concepção é um pequeno recorte, dá pra trabalhar muita aula, era um recorte muito pequeno, uma discussão de 10 minutos - bom pra aula - aí tem que dar outra aula, recorte pequeno, discussão de 5 minutos e vamo pra aula, só pra ir pontuando pro aluno as questões de História da Ciência. Mas mesmo assim eu acho difícil.

Esses diferentes dados reforçam a hipótese do projeto, de que a vivencia de todos os diferentes pilares agregam elementos formativos relevantes. A maioria dos estudantes dessa turma, especialmente no noturno, terminou o curso apresentando bom conhecimento da temática, de benefícios, de dificuldades, em localizar material, em preparar proposta, mas não consegui que eles vislumbrassem caminhos para a inserção da Escola Básica. Embora tenham desenvolvido propostas interessantes, a maioria achava que eram propostas teóricas, inadequadas para a escola básica. A imagem que comunicaram ainda é a de que a $\mathrm{HC}$ é algo mais a ser inserido, que só terão alguns minutos para isso.

É necessário realizar um empenho, para que todos os discentes possam conhecer propostas que foram implementadas na escola básica, por diferentes grupos de pesquisa e em diferentes escolas do Brasil. A turma do vespertino também apresentou algumas ressalvas, mas a maioria mostrava mais segurança para identificar e lidar com a pseudo-história e em localizar material 
adequado. Quanto à implementação, dependeria do contexto educacional. Apenas um dos estudantes disse não ter interesse em trabalhar com temas históricos, preferindo outras abordagens metodológicas.

Um dos estudantes mais resistentes à $\mathrm{HC}$ na turma do noturno, que se posicionava como cético com relação à abordagem da $\mathrm{HC}$ e dizia não se sentir capaz de implementá-la, traz um enfoque inusitado, um resultado que ainda não localizamos na literatura especializada: a $\mathrm{HC}$ em filmes como recurso para aproximar afetivamente o aluno, o professor e o conhecimento:

E8: "[...] e isso vai trazer o aluno pra perto de você $[\ldots]$ "o professor também vê a mesma coisa que eu" [...] toda vez que o aluno se lembrar do filme, ele vai se lembrar da situação e ele vai se lembrar do que você disse. $\mathrm{O}$ conhecimento que você passou pra ele vai tá atrelado ao sentimento, a uma recompensa que ele teve quando assistiu o filme, positiva, e vai ser uma lembrança bem mais forte do que se eu simplesmente falar que o raio não caiu na pipa do Franklin.

[...] se o aluno só conhece a história do Franklin pelo livro, não gera uma memória afetiva forte [...]

[...] estreita a relação com o conhecimento que você passa pra ele, e sedimenta de forma muito mais forte a emoção que ele teve quando jogou vídeo game ou viu o filme, do que quando eu falei do livro"(Grifos meus).

Assim como E8, outros discentes manifestaram uma postura cautelosa na entrevista. Mesmo os que se mostravam modestos, considerando tudo muito complexo, sentindo-se inseguros, chegam a propor outras estratégias para o uso da $\mathrm{HC}$ na escola básica. Ademais, vários deles reconhecem a importância dos temas em 
sua formação e comentam que sua visão se tornou mais crítica para todos os assuntos que leem e que são veiculados na grande mídia e em materiais didáticos, não apenas sobre a ciência e sobre a história das ciências.

No caderno de campo, os registros indicam que o início da proposta com essa turma foi um pouco frustrante. Na primeira aula deveríamos confrontar duas narrativas históricas, mas a maioria dos alunos não leu os dois textos. Alguns deles leram apenas um texto e "deram uma olhada" no outro. Foi necessário conduzir o início da discussão de modo expositivo, para que alguns pudessem perceber as enormes diferenças historiográficas entre os dois textos.

$\mathrm{O}$ esforço em inserir propostas comparativas entre diferentes narrativas históricas não é motivado pela abordagem ingênua da historiografia, mas pela mensagem prejudicial que ela deixa, em geral, reforçando os mitos do cientificismo e propagando visões estereotipadas sobre os produtos da ciência.

Um dos resultados desta etapa da pesquisa é a dificuldade que esse tema impõe, pela necessidade de leitura de vários artigos, especialmente para as turmas do noturno, em que os licenciandos trabalham durante o dia e tem pouco tempo para estudos extra sala.

\section{Refletindo sobre alguns resultados do projeto}

O recorte dos dados apresentados aqui, na forma de reflexões autobiográficas e em mensagens emitidas por uma das turmas que participou do processo formativo, permite-nos exemplificar respostas às questões que o projeto pretendia responder: Como e quando poderíamos realizar a inserção da $\mathrm{HC}$ e NDC? Que elementos poderiam orientar ações formativas? Em quais disciplinas? De que modo? Qual abordagem?

A análise da proposta de inserção longitudinal da $\mathrm{HC}$ e NDC ao longo da formação inicial de professores explicitou 
inúmeros benefícios formativos, assim como desafios, muitos deles previstos pela literatura e outros ainda inusitados. A descrição das propostas buscou oferecer exemplos de elementos e possibilidades, que se mostraram formativas, nas diversas disciplinas. A partir dessa vivência ao longo de oito anos, penso que foi o conjunto de ações planejadas e inter-relacionadas que promoveu a sinergia entre as abordagens, o principal elemento a contribuir para os bons resultados obtidos. Ainda que a apresentação dos dados tenha propositadamente trazido uma certa ênfase nas dificuldades, espera-se que os bons resultados, que também foram obtidos, puderam ser compreendidos.

O fato de terem sido trabalhados diferentes episódios históricos com os mesmos estudantes permitiu que eles vivenciassem exemplos da pluralidade metodológica das ciências, em seus aspectos epistêmicos e não epistêmicos, problematizando visões ingênuas ou essencialistas (FORATO et al., 2017). Ademais, foi possível mostrar que um mesmo episódio histórico recebe diferentes olhares, revelando a própria historiografia como uma atividade humana, e a construção de narrativas históricas também como uma atividade validada pela comunidade, dinâmica, contextualizada e datada. Tais discussões têm demonstrado promover a reflexão e a criticidade que extrapolam os conteúdos específicos da HC.

Observamos as críticas dos discentes ressonantes com a literatura: tempo didático requerido para um conteúdo de natureza epistemológica distinta, a cobrança dos pais com conteúdos para vestibular, a visão ingênua de que é preciso tirar física/ciências para colocar HC, falta ou dificuldade de localizar material didático adequado e falta de orientações metodológicas.

Ademais, vários licenciandos não acreditam na possibilidade de implementar $\mathrm{HC}$ na escola básica, mas o argumento parece ser preconceituoso ou mesmo um desestímulo para a inovação: "pelo perfil da escola e dos alunos, eles não acompanham a complexidade 
do conteúdo", vários deles posicionam-se. Nesses momentos, foi somente pelo fato de eu ter vivenciado a implementação de uma proposta complexa, em uma escola pública da periferia de São Paulo, discutindo sobre entes inobserváveis na ciência, o éter luminífero e as teorias sobre a natureza da luz no século XIX, que pude contra -argumentar (FORATO, 2009). Isso ressalta uma das dificuldades dos docentes formadores. Quantos puderam ter essa experiência?

Um problema que o projeto apontou, reforçando e ampliando o que a literatura já mostrou, é o desafio para o docente formador, quanto às abordagens da $\mathrm{HC}$ na formação de professores. Ao longo desses oito anos de implementação das propostas formativas no curso de Graduação em Ciências, em inúmeras turmas, foi possível vivenciar diferentes requisitos para o docente, além dos elementos já previstos para o formador de professores, na literatura já mencionada: Compreender e lidar com as fronteiras sobrepostas dos campos da ciência, da didática das ciências e da história e epistemologia das ciências, especialmente quando se busca a formação do professor reflexivo e pesquisador. Não se trata de apresentar receitas para o uso da HC, uma vez que elas não existem. Cada proposta é uma construção peculiar, para contextos singulares, mas essa reflexão autobiográfica aponta elementos implementados, alguns sucessos e desafios.

Desse modo, apesar de bons resultados do projeto formativo como um todo, reforçando a proposta dos pilares inseridos longitudinalmente no curso, e de resultados parciais em cada proposta, é preocupante constatar que nós, docentes formadores, temos muitos desafios a superar, especialmente aqueles que não tiveram essa formação temática em seu percurso de preparação como pesquisador. A despeito dos inúmeros resultados animadores que temos presenciado, muitos dos quais não foram apresentados aqui, um grande desafio é que tais iniciativas possam ser implementadas por outros formadores de professores, além daqueles que realizam pesquisas específicas nessa linha. No contexto do 
curso de Graduação em Ciências, da UNIFESP-Diadema, temos lidado com esses desafios estabelecendo parcerias entre os docentes, que vão desde a troca de materiais, até a participação em aulas de diferentes disciplinas.

Conhecer e compreender diferentes propostas implementadas na escola básica mostrou-se uma estratégia interessante, ainda mais quando agregada à possibilidade de os estudantes terem contato com a HC e a NDC em diversos momentos e disciplinas. Ao longo de sua formação, foi relevante este projeto ter mobilizado discussões teóricas, promover a vivência de elementos da futura prática profissional, avaliando materiais didáticos, localizando material adequado e preparando propostas didáticas, com enfoques na $\mathrm{HC}$.

Quando outros docentes assumiram algumas dessas disciplinas, algumas propostas foram adaptadas e outras mantidas quase na íntegra. As mudanças ocorreram em função do perfil de cada colega e de suas respectivas linhas de pesquisa, contribuindo para ampliar o escopo da proposta. Essas análises serão objeto de outros trabalhos.

Um outro desdobramento conjecturado é a criação de uma disciplina que perpasse os objetivos formativos propostos pelos pilares do projeto. Certamente que não se pretende solucionar o problema da preparação de professores para os usos da $\mathrm{HC}$, mas reforçar um empenho que deve ser pactuado e empreendido por diferentes docentes que atuam em um curso na formação de professores, em diferentes disciplinas e contextos.

\section{Referências}

ACEVEDO-DÍAZ, J. A.; GARCÍA-CARMONA, A.. «Algo antiguo, algo nuevo, algo prestado». Tendencias sobre la naturaleza de la ciencia en la educación científica. Revista Eureka sobre Enseñanza y Divulgación de las Ciencias, v.13, n.1, p.3-19, 2016. 
ALLCHIN, Doulgas. Pseudohistory and pseudoscience. Science \& Education, v.13, n.3, p.179-195, 2004.

ALLCHIN, Douglas. Evaluating knowledge of the nature of (whole) science. Science Education, v.95, n.3, p.518-542, 2011.

ALLCHIN, Douglas; ANDERSEN, Hanne; NIELSEN;

Keld. Complementary approaches to teaching nature of science: Integrating student Inquiry, Historical Cases, and Comtemporary Cases in the Classroom Practice. Science Education, v.98, n.3, p.461-486, 2014.

ANDRÉ, Marli. (Org) O papel da pesquisa na formação e na prática dos professores. Campinas: Papirus, 2010.

AZEVEDO, Nathália Helena; SCARPA, Daniela Lopes. Revisão Sistemática de Trabalhos sobre Concepções de Natureza da Ciência no Ensino de Ciências. Revista Brasileira de Pesquisa em Educação em Ciências (RBPEC). v.17, n.2 (2017): Maio-Agosto.

BALDINATO, José Otávio;. PORTO, Paulo Alves. Michael Faraday e A História Química de Uma Vela: Um Estudo de Caso Sobre a Didática da Ciência. Química Nova Na Escola. n.30, NOVEMBRO DE 2008.

BALDINATO, José Otávio. Conhecendo a química: um estudo sobre as obras de divulgação do início do século XIX. Tese de Doutorado em Ensino de Química. São Paulo: IQ-IF-IB-FE. Universidade de São Paulo, 2016.

BARDIN, Laurence. Análise de conteúdo [1977]. Lisboa: Edições $70,2000$. 
BRASIL. Conselho nacional de educação. Conselho pleno. Parecer CNE/CP 009/2001, de 8 de maio de 2001. Diretrizes Curriculares Nacionais para a Formação de Professores da Educação Básica, em nível superior, curso de licenciatura, de graduação plena. 2001.

BRASIL. Ministério da Educação e Cultura. Secretaria de Educação Média e Tecnológica. PCN+. Ensino Médio. Orientações Educacionais Complementares aos Parâmetros Curriculares Nacionais. Brasília: MEC/SEMTEC, 2002b.

BRASIL. CONGRESSO NACIONAL. CÂMARA DOS DEPUTADOS Ministério da Educação. LEI DE DIRETRIZES E BASES DA EDUCAÇÃO NACIONAL (LDB), Brasília: MEC: Lei no 9.394, de 20 de dezembro de 1996, Atualizada até 19/3/2015, 11. ed., 2015.

BORGES, Danielle Beatriz de Souza. A construção de uma abordagem histórica para o ensino de termodinâmica: Sadi Carnot e o estudo da Máquina Térmica. Dissertação de Mestrado em Ensino, História e Filosofia das Ciências e Matemática. Santo André:

Universidade Federal do ABC, 2016

BRUSH, S. G. Should the history of science be rated X? Science, v.183: 1164-1172, 1974.

CARVALHO, A. M. P.; GIL-PÉREZ, D. Formação de Professores de Ciências-Tendências e Inovações, São Paulo: Cortez, 2001.

CARVALHO, Anna Maria Pessoa de. Uma metodologia de pesquisa para estudar os processos de ensino e aprendizagem em salas de aula. In: SANTOS, F. M. T.; GRECA, I. M (Orgs.). A pesquisa 
em ensino de ciências no Brasil e suas metodologias. Unijuí: Ed. Unijuí, 2006, p.13-48.

CARDEIRA, Franscisco Aparecido. O uso do gás hidrogênio: dos aeróstatos aos ônibus da EMTU/SP e uma proposta para o ensino de ciências. Trabalho de Conclusão de Curso (Graduação em Ciências) - Universidade Federal de São Paulo, 2016.

CARDOSO, César. Ensino de Física na Escola Básica: Abordando a História da Ciência no Brasil. Trabalho de Conclusão de Curso. (Graduação em Ciências) - Universidade Federal de São Paulo: 2015.

CLOGH, Michael; OLSON, Joanne. Teaching and assessing the nature of science: An introduction. Science \& Education, v.17, n.2-3, p.143-145, 2008.

\section{D’AMBRÓSIO, Ubiratan. Educação para compatibilizar} desenvolvimento e sustentabilidade. Desenvolvimento e Meio Ambiente. Editora UFPR, v.15, p.11-20, jan./jun. 2007.

DEMO, P. Educar pela pesquisa. 4. ed., Campinas: Editora Autores Associados, 2000.

ERICSON, F. Qualitative research methods for science education. In: FRASER, B. J. e TOBIN, K. G. (Orgs.). International Handbook of Science Education, Part One, Kluwer Academic Publishers, 1998.

EL-HANI, Charbel N. Notas sobre o ensino de história e filosofia da ciênciana educação científica de nível superior. In: SILVA, C. (Org.). Estudos de história e filosofia das ciências. Subsídios para 
aplicação no Ensino. (p.3-21). São Paulo: Ed. Livraria da Física, 2006.

FERNANDES, Rubia.; PIRES, Flaviston ; FORATO, Thaís C. M. ; SILVA, JOSÉ A. Pinturas de Salvador Dalí para introduzir conceitos de mecânica quântica no ensino médio. Caderno Brasileiro de Ensino de Física, v.34, p.509-529, 2017.

FORATO, Thaís C. M.; BAGDONAS, Alexandre; TESTONI, Leonardo. Episódios históricos e natureza das ciências na formação de professores. Enseñanza de las ciencias - Digital, v. extra, p.3511-3516, 2017.

FORATO, Thaís. C. M. Preparação de professores para problematização da pseudohistória em materiais didáticos. Enseñanza de las Ciencias, v. Extra, p.1316-1321, 2013.

FORATO, Thaís C. M. A Natureza da Ciência como Saber Escolar: um estudo de caso a partir da história da luz. Tese de Doutorado em Educação. São Paulo: FEUSP, 2009. 2. vols.

FORATO, Thaís C. M.; GUERRA, A. ; BRAGA, M. .

Historiadores das ciências e educadores: frutíferas parcerias para um ensino de ciências reflexivo e crítico. Revista Brasileira de História da Ciência, v.7, n.21, p.137-141, 2014.

FORATO, Thaís C. M.; MOURA, B. A.. Introdução. História e Epistemologia das Ciências na formação de professores. In: Breno Arsioli Moura; Thaís Cyrino de Mello Forato. (Org.). Histórias das Ciências, Epistemologia, Gênero e Arte. Ensaios para a formação de professores. $1^{\mathrm{a}}$ ed. Santo André: Editora da UFABC. 2017, v. Único, p.1-10. 
FORATO, Thaís C. M; PIETROCOLA, Maurício; MARTINS, Roberto De Andrade. Historiografia e natureza da ciencia na sala de aula. Caderno Brasileiro de Ensino de Física, v.28, n.1, p.27$59,2011$.

FREIRE, Paulo. Pedagogia da autonomia: saberes necessários à prática educativa. 42a reimpressão. São Paulo: Paz e Terra, 1996.

GIL PÉREZ, D.; MONTORO, I. F.; ALIS, J. C.; CACHAPUZ, A.; PRAIA, J. Para uma imagem não deformada do trabalho científico. Ciência \& Educação v.7, n.2, p.125-153, 2001.

GUILGER, F. J. ; FORATO, T. C. M. . A Divina Comédia de Alighieri e o geocentrismo medieval na Escola Básica. In: XXI Simpósio Nacional de Ensino de Física, 2015, Uberlândia. Enfrentamentos do Ensino de Física na Sociedade Contemporânea. Uberlândia/ São Paulo: UFU, UFTM, SBF, 2015, v.1, p.1-8.

HABERMAS, J. Conhecimento e interesse. In: HABERMAS, J. Técnica e ciências como“ideologia”. Lisboa: Edições 70, 2006, p.129-147.

HÖTTECKE, Dietmar; SILVA, Cibelle Celestino. Why Implementing History and Philosophy in School Science Education is a Challenge: An Analysis of Obstacles. Science \& Education v.20, n.3, p.293-316, 2011.

HOLTON, Gerald. What historians of science and science educators can do for one another? Science Education v.12, n.7, p.603-616, oct. 2003.

KRAGH, H. An introduction to the historiography of science. Cambridge: Cambridge U.P, 1987. 
KUHN, T. A The Structure of Scientific Revolutions.: Chicago: University of Chicago Press, 1962.

LABURU, Carlos Eduardo; ARRUDA, Sérgio de Mello; NARDI, Roberto. Pluralismo metodológico no ensino de ciências. Ciência \& Educação.v.9, n.2, p. 247-260, 2003

LÜDKE, M. A complexa relação entre o professor e a pesquisa. In ANDRÉ, M. (Orgs.). O papel da pesquisa na formação e na prática dos professores. 11. ed. Campinas: Papirus, 2010.

MARTINS, André F. P. História e filosofia da ciência no ensino: há muitas pedras nesse caminho. Caderno Brasileiro de Ensino de Física v.24, n.1, p.112-131, 2007.

MARTINS, Roberto de Andrade. Introdução: a história da ciência e seus usos na educação. In SILVA, CIBELLE C. (Org.). Estudos de história e filosofia das ciências: subsídios para aplicação no ensino. São Paulo: Editora Livraria da Física, 2006.

MARTINS, Roberto de Andrade. Ciência versus historiografia: os diferentes níveis discursivos nas obras sobre história da ciência. In: ALFONSO-GOLDFARB, A. M.; BELTRAN, M. H. R. Escrevendo a história da ciência: tendências, propostas e discussões historiográficas. São Paulo: Educ; Fapesp; Editora Livraria da Física, 2004, p.115-145.

MARTINS, R. de A. Como não escrever sobre história da física - um manifesto historiográfico. Revista Brasileira de Ensino de Física, v.23, n.1, p.113-129, 2001.

MARTORANO, Simone A. A transição progressiva dos modelos de ensino sobre cinéticaquímica a partir do desenvolvimento 
histórico do tema. Tese de Doutorado em Ensino de Química. São Paulo: IQ-IF-IB-FE. Universidade de São Paulo, 2012.

MATTHEWS, Michael R. History, philosophy and science education: the present reapproachment. Science \& Educationv.1, n.1, p.11-47, 1992.

MEDEIROS; A.; BEZERRA FILHO, S. A natureza da ciência e a instrumentação para o ensino da física. Ciência \& Educação v.6, n.2, p.107-117, 2000.

MOURA, Breno Arsioli. Formação crítico-transformadora de professores de Física: uma proposta a partir da História da Ciência, 2012. Tese (Doutorado - Ensino de Física) - Faculdade de Educação, IF, IQ IB, FE. Universidade de São Paulo, São Paulo, 2012.

NEVES, Defferson R. M.; PEREIRA, Bianca A.; PEREIRA, Sabrina A.; FORATO, Thaís C. M; BIANCO, A. The Wiechert, Kaufmann and Thomson experiments on the charge/mass of the particles of the cathode rays. In: 1st European Regional IHPST Conference, 2016, Flensburg, Germany. Online Publication Abstracts. http://ihpst.clubexpress.com/: IHPST, 2016.

OLIVEIRA, Denize C. de. Análise de conteúdo temático-categorial: uma proposta de sistematização. Revista de Enfermagem da UERJ, v.16, n.4, p.569-576, out./dez., 2008.

OLIVEIRA, Roberto D. V. L.; QUEIROZ, Gloria R. P. C.. Educação em Ciências e Direitos Humanos: reflexão-ação em/ para uma sociedade plural. Rio de Janeiro: Editora Multifoco, 2013. 
OLIVEIRA, W. C.; DRUMMOND, J. M. HIDALGO F.

Refletindo sobre desafios à inserção didática da História e Filosofia da Ciência em oficina de formação docente. Alexandria (UFSC), v.8, p.151-179, 2015.

PAGLIARINI, Cassino Rezende. Uma análise da história e filosofia da ciência presente em livros didácticos de física para o ensino médio. Dissertação de Mestrado em Física Básica. São Carlos: IF. Universidade de São Paulo, 2007.

PASSEGGI, Maria da Conceição; SOUZA, Elizeu Clementino De Souza; VICENTINI, PAULA PERIN. Entre a vida e a formação: pesquisa (auto) biográfica, docência e profissionalização. Educação Revista. v.27 n.1, Belo Horizonte Apr., 2011.

PEDUZZI, L. Sobre a utilização didática da história da ciência. In: PIETROCOLA, M. (Org.). Ensino de Física - conteúdo, metodologia e epistemologia numa concepção integradora. Florianópolis: Editora UFSC, 2001.

PEREIRA, A. K. S; FORATO, THAÍS C. M. Uma proposta para o ensino contextualizado de Hidrostática. Em: XV Encontro de Pesquisa em Ensino de Física, v. online, p.1-8, 2014.

PERON, T; GUERRA, Andreia ; FORATO, Thaís C. M. Linha do Tempo: controvérsia entre a contextualização de episódios históricos e a imagem da construção linear da ciência. In: XIV Encontro de Pesquisa em Ensino de Física, 2012, Maresias. Atas do XIV Encontro de Pesquisa em Ensino de Física. Maresias: SBF, 2012, v. Único. p.1-9. 
PIMENTA, S. G.; GHEDIN, E. (orgs.). Professor Reflexivo no Brasil: gênese e crítica de um contexto. 7. ed. São Paulo: Cortez Editora, 2012.

PORTO, P. A.; "História e Filosofia da Ciência no Ensino de Química: em busca dos objetivos educacionais da atualidade". In: SANTOS, W. L. P. \& MALDANER, O. A. (org.), Ensino de Química em Foco, Ijuí: Editora Unijuí, 2010, p.159-180.

PUMFREY, S. History of science in the National Science Curriculum: a critical review of resources and their aims. British Journal of History of Science v.24, n.1, p.61-78, 1991.

REIS, J. C.; GUERRA, A.; BRAGA, M.. 2006: Ciência e arte, relações improváveis? História, ciências, saúde - Manguinhos. v.13 - suplemento, p.71-87, 2006.

ROSENTALSKY, Evandro Fortes. Indo além da natureza da ciência: o filosofar sobre a Química por meio da ética química. 2018. Tese (Doutorado em Ensino de Química). Universidade de São Paulo, São Paulo, 2018.

SANTOS, M. E. Encruzilhadas de mudança no limiar do século XXI: co-construção do saber científico e da cidadania via ensino CTS de ciências. In: II Encontro Nacional De Pesquisa Em Educação Em Ciências. Atas... Valinhos, v.2, 1999.

SCHMIEDECKE, Winston Gomes. A história da ciência nacional na formação e na prática de professores de física. Tese de Doutorado em Ensino de Física. São Paulo: IF. Universidade de São Paulo, 2016. 
VITAL, Abigail; GUERRA, Andreia. A implementação da história da ciência no ensino de física: uma reflexão sobre as implicações do cotidiano escolar. Ensaio: pesquisa em educação em ciências (online), v.19, p.1-21, 2017.

VITAL, A.; GUERRA, A. Textos para ensinar física: princípios historiográficos observados na inserção da história da ciência no ensino. Ciência \& Educação, v.22, p.351-370, 2016.

VILLANI, A.; PACCA, J. L. A.; FREITAS, D. Science Teacher Education in Brazil: 1950-2000. Science \&Education v.18, n.1, p.125-148, 2009.

WHITTAKER, M. A. B. History and quasi-history in physics education - Part 1. Physics Education v.14, p.108-112, 1979.

ZANETIC, João. Física e Arte: uma ponte entre duas culturas. Pro-Posições, v.17, n.1 (49) - jan./abr. 2006. 